\title{
On Agile Metrics for Operations Management: Measuring and Aligning Agility with Operational Excellence
}

\author{
A.M. Carvalho ${ }^{1,2,3^{*}}$, P. Sampaio ${ }^{2}$, E. Rebentisch ${ }^{3}$ \\ ${ }^{1}$ MIT Portugal Program, Engineering Design and Advanced Manufacturing Focus Area, Portugal/ US \\ ${ }^{2}$ Centro ALGORITMI; Department of Production and Systems Engineering, University of Minho, Portugal \\ ${ }^{3}$ Sociotechnical Systems Research Center, Massachusetts Institute of Technology, US \\ *Corresponding author: andre.carvalho@dps.uminho.pt, andremc@,mit.edu
}

\begin{abstract}
High-quality performance in Operations Management has been measured through different Excellence frameworks, with special emphasis on Operational Excellence models. By allowing to track performance indicators, identify improvement opportunities, and tackle operational limitations, such frameworks have proven their validity throughout the years. However, and despite their history of success, these frameworks remain based on almost the same principles and criteria that were defined when they were first being established, more than three decades ago. As change becomes central to the life of organizations, the ability to reconfigure operations becomes vital for success. However, the current takes on Operational Excellence do not consider the ability to change in their assessments. In a marketplace in transformation, this is perceived as a limitation and draws criticism to Excellence frameworks. In the face of this gap, we develop, deploy and analyze the results obtained by an Organizational Agility assessment framework that is aligned with Excellence in Operations Management. This paper presents this process and highlights the main results of bringing Organizational Agility together with Operational Excellence in the measurement and pursuit of superior operational performance.
\end{abstract}

Keywords - Operational Excellence, Operations Management, Organizational Agility, Quality Management

\section{INTRODUCTION}

Operational Excellence (OpEx) has been consistently used to measure, assess, and improve operations, managing and integrating different dimensions in search for improved performance throughout the organization [1]. There are different Excellence frameworks, some more oriented to operations [2], others promoting Excellence with a broader business perspective and including OpEx within this scope [3]. Despite this variety, and through years of continued use, these frameworks proved to be successful in promoting superior performance, while being efficient tools to measure organizational capabilities and allow the (self-) assessment of processes and operations [1]. However, and in recent years, limitations started to be more visible, with reports of Operational Excellence programs stagnating or being unable to continuously lead to performance improvements [4]. At the same time, the number of applicants in some of the best-know Excellence programs has been decreasing steadily, showing clear signs of disengagement from manufacturing and service organizations [5]. To a certain extent, some of these problems may be explained by the fact that these models and programs have seen little evolution over the years, not having adapted to changing business circumstances [6]. This is critical, as the complexity around Operations Management is only increasing. Organizations worldwide deal with new market trends and demands, disruptive technologies, and reinforced competition. Value chains became longer, more global, and more exposed to interruption. Much of this complexity has been framed within the so-called "VUCA" environment: business realities marked by volatile, uncertain, complex and ambiguous settings. In these environments, change is frequent and often unexpected, and organizations must learn to deal with sudden shifts, building resilience and incorporating change in their pursuit of success [1]. However, there is so far no defined framework that defines and measures success factors in dealing with change.

We believe that such a framework is nowadays an essential tool for managing operations and promote highquality performance. Accordingly, the goal of this work is twofold: to development a framework that (1) can be used to assess Organizational Agility in different industrial settings, and that (2) allows to link those assessment results with Operational Excellence, bringing together these two concepts in the search for superior performance in Operations Management.

Exploring the gaps identified in literature regarding the relationship between OpEx and Agility (Section II), we design and develop an Organizational Agility assessment scale (Sections III and IV). In order to assure its fit to the industrial environment and easy practical deployment, it was then tested in a total of 6 organizations (Sections IV). Results show that the framework was able to successfully measure Organizational Agility, and also to link those results to Operational Excellence. This work further uncovered how the two concepts relate, identifying how certain organizational capabilities are either catalyzed or impaired by the existing OpEx enablers (Section V).

\section{LITERATURE REVIEW}

A. Excellence as a means to achieve superior performance in Operations Management

Operations management has seen several different approaches for the promotion of superior quality and performance - to a point where some of these tools and frameworks come to be perceived as competing [6]. However, when it comes to discussing the achievement of highly differentiating results, the success of Excellence frameworks is undeniable. Organizations that deploy them 
achieve better outcomes that the market average [7], increasing financial, productivity, and quality metrics $[7,8]$.

There are dozens of different Excellence frameworks in use across the world. However, most of them are based on the structures and principles of the most used and wellestablished Excellence models and awards, such as the Shingo Model for Operational Excellence, the Excellence Model of the European foundation for Quality Management (EFQM) or the Baldrige Excellence Framework. Although developed with different regional backgrounds - they show some differences in their structures, criteria and principles - they were designing with a similar goal in mind: providing a quality-oriented framework for organizations to improve performance and obtain superior results [9].

\section{B. Finding sustainability in Excellence}

One topic where these frameworks clearly align is in highlighting the importance of sustaining Excellence throughout time, and the vital importance of involving people and developing the organizational culture to achieve this sustainability. This becomes clear from the arguments presented by promoters of these frameworks regarding the successful development and deployment of tools, methods, and strategies related with Excellence. Both the European Foundation for Quality Management or the Malcom Baldrige National Quality Award let this perspective transpire when they argue the use of excellence frameworks to, besides process and operations improvement results, "instill a culture of Excellence" [10] or "solidify a culture of Organizational Excellence" [11].

Despite this focus on long-term sustainability, not all organizations that start their journeys in Excellence are successful. One reason presented this failure is the inability shown by some organizations to pursue Excellence in the long-term. As they look at Excellence with a single-use perspective, these organizations tend to invest all efforts in the implementation phase, neglecting its sustainability. Even as organizations pursue cultural alignment, they do so in the perspective of fitting the excellence framework to the existing culture. As a result, they disregard the development of that culture and do not push new strategic choices to truly promote an enduring excellence orientation [1].

\section{Bringing Organizational Agility together with Operational Excellence}

On top of this limited approach to Excellence, new challenges and limitations have been pointed to its frameworks and programs in recent years. In great part, they derive from changing market realities, including the dawn of the fourth industrial revolution. In this scenario, the pressure to effectively and efficiently deal with change has become a top priority for many organizations. However, there have been no sustained effort to integrate this necessity in the existing approaches to Operational Excellence - especially in a way that allows a structured framework that integrates people, processes and technology in the scope of making an organization more agile. Excellence frameworks remain mostly based on the same principles and criteria that were defined when they were established, more than three decades ago. There have been some effective steps to close this gap, but they were limited. The MBNQA has for some time considered Agility as part of its core concepts [11], and more recently, the EFQM included in its fundamental concepts the importance of "managing with agility" [12]. However, neither of these provides a structured approach to the assessment of agility or its inclusion in the assessment of performance Excellence.

Similarly, several scholarly works have explored the existing limitations in bringing agility into the orbit of Operational Excellence. Some focus on the need to shift the focus of Operational Excellence from its optimization perspective into the long-term sustainability perspective $[1,12]$. Others point that OpEx is traditionally more focused on working practices of Lean Management and Continuous Improvement, and argue for the need of, in an evolving market place, considering principles of Agile Manufacturing to meet the demands of increasingly customized products and shorter life cycles [13].

However, and despite these perspectives and moves, the truth is that there is still no practical approach that allows the measurement of Agility in the scope of Operations Management, and the assessment of the capabilities of organizations to promote Excellence in an adaptable, long-lasting way. In the face of this gap, we present in this work an Organizational Agility assessment framework that is aligned with Excellence in the scope of the management of Operations.

\section{MODEL DESIGN}

\section{A. Structure}

In order to structure such assessment framework, and based on several practical and theoretical examples collected, we opted for the use of capability maturity models. In fact, the use of these models in the scope of the management of processes and operations is widespread. They have been used in the development of several assessment frameworks, such as the Capability Maturity Model Integration (CMMI), the Project Management Maturity Model, or the EFQM Excellence Model [14,15]. Although there is no Agility assessment scale in use with this structure - only a theoretical proposal to do so [16] maturity models have been used to assess organizational capabilities in several areas, and there are no apparent limitations to their use in the scope of Agility. Furthermore, and having in mind our goal of integrating the results achieved by this framework in measuring Agility with those obtained for Operational Excellence, using a similar structure to that traditionally used on OpEx will allow an easier and more efficient translation and comparison of the results.

Capability maturity models can have different representations and uses. In the scope of this work, and given our focus on the different capabilities of 
Organizational Agility and the ability to assess them individually, we opted for the continuous representation [17].

TABLE 1 presents the different levels of this representation, as well as their description and score range.

TABLE 1

MATURITY CAPABLITY SCALE. CONTINUOUS REPRESNETATION

\begin{tabular}{|c|c|c|}
\hline Level & Description & Score \\
\hline Level 0 & Not present & $0 \%$ \\
\hline Level 1 & Performed & $1 \%-20 \%$ \\
\hline Level 2 & Managed & $21 \%-40 \%$ \\
\hline Level 3 & Defined & $41 \%-60 \%$ \\
\hline Level 4 & Quantitatively Managed & $61 \%-80 \%$ \\
\hline Level 5 & Optimizing & $81 \%-100 \%$ \\
\hline
\end{tabular}

\section{B. Agile enablers for assessment}

Once defined the assessment framework's structure, the next step was to identify the elements to be assessed and measured through it. These elements represent the measures of agility, and will allow a snapshot of the current state of agility in a given organization. Maturity models assess organizations on their capabilities organizational competencies that enable a certain concept to be developed, deployed and improved [12, 18]. These enabling elements have been listed for several different concepts. In the scope of Agility, several authors have taken this effort. Earlier works, dating from the 1990's, list process and manufacturing flexibility, and the use of technology and information systems as vital for Agility [19]. In the past two decades, however, and in the face of a reinforced interest on organizational agility, a new wave of works focused on these enablers. In the late 2000's, different authors highlighted ideas such as the promotion of more horizontal organizations and the development of people [20, 21]. Examples of that are enablers such as work environment, human resources development, the definition of project management teams and the structure of the organization [20,21]. Many of these ideas have been reinforced later, as the focus on project management and the use of agile methods became more common in different industries, with reinforced focus on the development of both products and services [22]. Furthermore, and in face of increasingly disrupted and complex operations, enablers related to agile strategy, change management and improved communication started to gain attention $[22,23]$. Table 2 shows these enablers, as well as the practical evidence used to identify each one.

The second goal of this work is to compare and integrate the results of measuring agile enablers with those of OpEx. For the purpose of clarifying the measures used on the assessment of Excellence, as well as the relationships promoted between the enablers of the two concepts, Excellence enablers and evidence are also listed in this table. OpEx enablers were collected from the main frameworks described above: The Shingo Model for Operational Excellence [2], the EFQM Excellence Model [11], and the Baldrige Excellence framework [12].
TABLE 2

ENABLERS OF ORGANIZATIONAL AGILITY, PRACTICAL EVIDENCE AND RELATED EXCELLENCE ENABLERS

\begin{tabular}{|c|c|c|}
\hline Enablers & Evidence & $\begin{array}{c}\text { Related Excellence } \\
\text { Enablers and } \\
\text { Evidence }[2,10,11]\end{array}$ \\
\hline $\begin{array}{l}\text { Work } \\
\text { Environment }\end{array}$ & $\begin{array}{l}\text { Agile mindset, } \\
\text { Collaborative work; } \\
\text { recognition }\end{array}$ & $\begin{array}{l}\text { Cultural Orientation; } \\
\text { Teamwork; }\end{array}$ \\
\hline $\begin{array}{l}\text { Human } \\
\text { Resources }\end{array}$ & $\begin{array}{l}\text { Development of new } \\
\text { skills; } \\
\text { Knowledge } \\
\text { management }\end{array}$ & $\begin{array}{l}\text { Employee engagement; } \\
\text { Training; } \\
\text { Motivation; } \\
\text { Recognition }\end{array}$ \\
\hline $\begin{array}{l}\text { Project } \\
\text { Management }\end{array}$ & $\begin{array}{l}\text { Autonomy and } \\
\text { empowerment; } \\
\text { Cross-functionality; }\end{array}$ & $\begin{array}{l}\text { Stakeholder } \\
\text { involvement in projects; } \\
\text { Design for } \\
\text { use/manufacturing. }\end{array}$ \\
\hline $\begin{array}{l}\text { Organizational } \\
\text { structure }\end{array}$ & $\begin{array}{l}\text { Decentralized } \\
\text { decision-making } \\
\text { Interdepartmental } \\
\text { collaboration }\end{array}$ & $\begin{array}{l}\text { Silo reduction/ } \\
\text { elimination; } \\
\text { Governance system. }\end{array}$ \\
\hline $\begin{array}{l}\text { Technical } \\
\text { flexibility }\end{array}$ & $\begin{array}{l}\text { Automation; } \\
\text { Speed; } \\
\text { Flexibility; } \\
\text { Reconfiguration }\end{array}$ & $\begin{array}{l}\text { Quality assurance and } \\
\text { error proofing; } \\
\text { Maintenance } \\
\text { Engineering. }\end{array}$ \\
\hline $\begin{array}{l}\text { Process } \\
\text { flexibility }\end{array}$ & $\begin{array}{l}\text { Process concurrency } \\
\text { Process integration } \\
\text { Frequent revision } \\
\text { cycles }\end{array}$ & $\begin{array}{l}\text { Quality Management; } \\
\text { Process Revision. }\end{array}$ \\
\hline $\begin{array}{l}\text { Product/Service } \\
\text { Development }\end{array}$ & $\begin{array}{l}\text { Newness } \\
\text { Complexity } \\
\text { Balance of project } \\
\text { management methods }\end{array}$ & $\begin{array}{l}\text { New market } \\
\text { development and } \\
\text { current } \\
\text { market exploitation. }\end{array}$ \\
\hline $\begin{array}{l}\text { Information } \\
\text { Systems }\end{array}$ & $\begin{array}{l}\text { Technology; } \\
\text { Connectivity; } \\
\text { Digitalization }\end{array}$ & $\begin{array}{l}\text { Information technology; } \\
\text { Analyze data and } \\
\text { information. }\end{array}$ \\
\hline Strategy & $\begin{array}{l}\text { Leadership Unity } \\
\text { Data-driven decision } \\
\text { making; } \\
\text { Product succession } \\
\text { planning }\end{array}$ & $\begin{array}{l}\text { Strategy development; } \\
\text { Strategy deployment; } \\
\text { Align systems; } \\
\text { Align strategy; }\end{array}$ \\
\hline $\begin{array}{l}\text { Change } \\
\text { Management }\end{array}$ & $\begin{array}{l}\text { Strategic Sensitivity; } \\
\text { Prioritization; } \\
\text { Resource fluidity }\end{array}$ & $\begin{array}{l}\text { Voice of the customer; } \\
\text { Data-based } \\
\text { decisions and actions. }\end{array}$ \\
\hline Communication & $\begin{array}{l}\text { Easy access to } \\
\text { information } \\
\text { Open information } \\
\text { sharing }\end{array}$ & $\begin{array}{l}\text { Strategy } \\
\text { Communication; } \\
\text { Communication } \\
\text { processes. }\end{array}$ \\
\hline
\end{tabular}

\section{METHODOLOGY AND MODEL DEPLOYMENT}

\section{A. Agile Assessment Framework}

With the structure, enablers and evidence for data collection defined, the last step before advancing to the practical deployment and testing of the model was to assemble these components and present our Organizational Agility Assessment Scale. The assessment scale, following the traditional structure found in maturity model scales, features the enablers and the different assessment levels in a table format. Enablers are listed vertically, while the different levels are presented horizontally. The score for each enabler is then listed in the intersection between the corresponding components. For the purpose of estimating the final assessment score for Organizational Agility, the average score of all assessed enablers is calculated. Table 3 shows the assessment scale, and provides an example on scores how scores are calculated, for explanatory purposes. 
TABLE 3

ORGANIZATIONAL AGILITY ASSEMENT SCALE Example, for explanatory purposes.

\begin{tabular}{|c|c|c|c|c|c|c|}
\hline & $\begin{array}{c}\text { Level } 0 \\
0 \%\end{array}$ & $\begin{array}{c}\text { Level } 1 \\
1-20 \%\end{array}$ & $\begin{array}{l}\text { Level } 2 \\
21-40 \%\end{array}$ & $\begin{array}{l}\text { Level } 3 \\
41-60 \%\end{array}$ & $\begin{array}{c}\text { Level } 4 \\
61-80 \% \\
\end{array}$ & \begin{tabular}{|c|} 
Level 5 \\
$81-100 \%$ \\
\end{tabular} \\
\hline \begin{tabular}{|l|} 
Work \\
Environment \\
\end{tabular} & & & $35 \%$ & & & \\
\hline \begin{tabular}{|l|} 
Human \\
Resources \\
\end{tabular} & & & & & $65 \%$ & \\
\hline \begin{tabular}{|l|}
$\begin{array}{l}\text { Project } \\
\text { Management }\end{array}$ \\
\end{tabular} & & & & $45 \%$ & & \\
\hline $\begin{array}{l}\text { Organ. } \\
\text { structure }\end{array}$ & & & & $60 \%$ & & \\
\hline $\begin{array}{l}\text { Technical } \\
\text { flexibility } \\
\end{array}$ & & & $39 \%$ & & & \\
\hline \begin{tabular}{|l|} 
Process \\
flexibility \\
\end{tabular} & & & & & $62 \%$ & \\
\hline Development & & & & $58 \%$ & & \\
\hline $\begin{array}{l}\text { Information } \\
\text { Systems }\end{array}$ & & & & $55 \%$ & & \\
\hline Strategy & & & & $48 \%$ & & \\
\hline \begin{tabular}{|l|} 
Change \\
Management
\end{tabular} & & & & & $61 \%$ & \\
\hline Communication & & & & $59 \%$ & & \\
\hline
\end{tabular}

\section{B. Deployment and Testing}

Once the framework was developed, it was necessary to test it. This effort focused not only in ascertaining if the framework and the data collection methods were able to efficiently identify and measure Organizational Agility enablers, but also if its results integrated well with the assessment of OpEx enablers.

The framework was tested in a total of six organizations, where it was combined with the assessment of Operational Excellence. This OpEx assessment framework followed the same scaling structure and considered the enablers listed in Section III (Model Design). These were collected form the most well-known Excellence frameworks: the EFQM Excellence Model, Baldrige Excellence Framework, and the Shingo Model for Operational Excellence (see table 2, column 3 for related OpEx enablers measured).

Multiple organizations within diverse industries were used as test beds, in an effort to ensure that the framework was able to adapt to different business environments. With Operational Excellence and Organizational Agility being pursued in different industries, a truly useful framework needed to work independently of the environment where it was deployed. Accordingly, the six organizations studied have different sizes (although only medium and large organizations were considered), locations (divided between Europe and the US), and operate in different industries. In common they have the fact that they are matured organizations (more than 15 years of activity) and the fact that they operate in highly technical and technological industries, being especially exposed to change and disruption within their marketplaces.

\section{Data Collection and Analysis}

In order to promote a deep study of the reality of each organization, a case study methodology was followed. A total of 6 organizations was studied. Each case took, on average, 5 weeks. Data was collected at different organizational levels (3 levels were defined: leadership, management, and associates) and functional parts (technical and commercial). Data collection was based on the use of questionnaires, interviews and focus groups, analysis of documentation, including different business reports, and the review of key performance indictors and process flow charts. Although a point of contact or a group of people were defined in each of the organizations to facilitate data collection, the actual collection was performed integrally by the research team.

Scales describing the different maturity levels were defined for each enabler, with the evidence and methods used to collect data and assess the related capabilities being described to ensure research quality, reliability and repeatability. Accordingly, all 6 organizations were assessed under the same criteria and using the same methods.

After data collection, the analysis was performed resorting to qualitative analysis software. It included the review and analysis of different corporate documents, interviews, surveys, and observation.

A similar process was used for the assessment of the enablers of Organizational Agility and Operational Excellence.

\section{RESULTS}

This study achieved positive results in both its proposed objectives: the development of an assessment framework that is able to measure agile capabilities across different organizations and industries, and the ability to, in each organization, relate the assessment results with the current performance in terms of Operational Excellence.

We consider the assessment framework to be sufficiently validated as, in all six performed studies, the research team was able to retrieve the necessary evidence to generate assessment scores, and to do so following a similar methodology. Although after each case the methods were reviewed and some improvement opportunities were identified, this has not led to significant differences in the methodology used for data collection and analysis. Accordingly, a consistent approach was used for identifying the evidence listed in table 2, and to perform the and score each organization as shown in table 3. Furthermore, the success of this framework - and the validity of the identified enablers and evidence used to support this assessment - is also reinforced by the positive reception of the results by each of the organizations studied.

Also in regards to the integration and comparison with the enablers of Operational Excellence this study achieved positive and consistent results. The integrated analysis of Organizational Agility and Operational Excellence led to three different situations being identified as a result of the relationship between these two concepts:

(1) Organizations were agility was potentiated by wellsustained, enduring use of excellence programs. One case (Organization 2, see table 4) clearly showed how a strong investment in Operational Excellence paved way for more 
flexible processes, nimble strategy deployment and a cultural alignment that supports the efforts to adapt and anticipate changes in the market.

(2) Organizations were further development of Agility is dependent on/could benefit from further development of Excellence initiatives. Two cases (org. 3 and 5) showed limitations in achieving broader agile deployment across the organization due to limitations that could be addressed by OpEx initiatives. Examples are silo elimination, cultural alignment with strategic goals, and the creation of a customer/value orientation on back-to-back processes. (3) Agility constrained by the lack of sustained, enduring excellence initiatives. Three cases (org. 1, 4 and 6) showed how limited engagement with OpEx severely constrained the possibility of developing Agile capabilities and enablers. Amongst the missing OpEx enablers in these organizations are teamwork, employee engagement, or people development/ training.

This integrated analysis allowed to identify real improvement opportunities for organizations to improve their performance, in an integrated way, both in terms of Excellence and Agility. Table 4 shows the results of the assessment of Agility in each organization, and summarizes the relationship between the two concepts.

TABLE 4

CASE STUDY RESULTS

\begin{tabular}{|c|c|c|}
\hline Org. & Level (Score, \%) & Relationship with Excellence \\
\hline 1 & Level 3 (51\%) & $\begin{array}{c}\text { Agility constrained by the lack of } \\
\text { sustained, enduring excellence initiatives }\end{array}$ \\
\hline 2 & Level 4 (73\%) & $\begin{array}{c}\text { Agility potentiated by well-sustained, } \\
\text { enduring use of excellence programs }\end{array}$ \\
\hline 3 & Level 4 (75\%) & $\begin{array}{c}\text { Agile development could benefit from } \\
\text { further engagement with Operational } \\
\text { Excellence }\end{array}$ \\
\hline 4 & Level 4 (61\%) & $\begin{array}{c}\text { Agility constrained by the lack of } \\
\text { sustained, enduring excellence initiatives }\end{array}$ \\
\hline 5 & Level 4 (67\%) & $\begin{array}{c}\text { Agile development dependent from further } \\
\text { engagement with Operational Excellence }\end{array}$ \\
\hline 6 & Level 3 (53\%) & $\begin{array}{c}\text { Agility constrained by lack of sustained, } \\
\text { enduring excellence initiatives }\end{array}$ \\
\hline
\end{tabular}

\section{CONCLUSIONS}

Overall results show the capacity of this framework in assessing Organizational Agility, as well as in integrating it and comparing the performance of its enablers with the enablers of Operational Excellence. Furthermore, these results also help to understand key elements for sustaining operational excellence in the long term. Accordingly, this work was able to meet its goals to assess Organizational Agility and bring it together with Operational Excellence, promoting a more agile perspective for the fields of Quality and Operations Management. Limitations and future work opportunities include promoting a larger number of case studies, and exploring in detail the correlations between enablers.

\section{ACKNOWLEDGMENTS}

This work has been supported by national funds through FCT - Fundação para a Ciência e Tecnologia within the Project Scope: UID/CEC/00319/2019, as well as by $\mathrm{PhD}$ grant $\mathrm{PD} / \mathrm{BD} / 114149 / 2016$.

\section{REFERENCES}

[1] Carvalho AM, Sampaio P, Rebentisch E, Carvalho JÁ, Saraiva P. "Operational excellence, organisational culture and agility: the missing link?”. Total Qual. Manag \& B. Excellence. pp 1-20, 2017

[2] Shingo Institute. "Assessment Criteria". No date.

[3] Lu, Dawei, Alan Betts, and Simon Croom. "Re-investigating business excellence: Values, measures and a framework." Total Qual. Manag \& Business Excellence 22, no. 12, pp. 1263-1276. 2011.

[4] Bertels, Thomas, and Arne Buthmann. "Raise the bar." Quality Progress 46, no. 8, pp. 28-32. 2013.

[5] AM Carvalho, P Sampaio, E Rebentisch. "Business Excellence Models: supporting the cultural perspective to operationalize excellence sustainability in manufacturing organizations". 3rd North American Industrial Eng. and Operations Management. 2018.

[6] S. Russell, "ISO 9000:2000 and the EFQM Excellence Model: Competition or co-operation?," Total Qual. Manag., vol. 11, no. 4-6, pp. $657-665,2000$

[7] Hendricks, Kevin B., and Vinod R. Singhal. "Does implementing an effective TQM program actually improve operating performance? Empirical evidence from firms that have won quality awards." Management science 43, no. 9, pp. 1258-1274, 1997.

[8] Chakravorty, Satya S., J. Brian Atwater, and James I. Herbert. "The Shingo Prize for operational excellence: rewarding world-class practices." Int Journal of Business Excellence 1, no. 4, pp. 418-433, 2008

[9] Talwar, Balvir. "Business excellence models and the path ahead...." The TQM Journal 23, no. 1 (2011): 21-35.

[10] European Foundation for Quality Management, "EFQM Excellence Model". Brussels, 2012

[11] NIST, "Baldrige National Quality Program - The Path to Excellence and Some Path-Building Tools". May, 2019.

[12] Jaeger, A., K. Matyas, and W. Sihn. "Development of an assessment framework for Operations Excellence (OsE), based on the paradigm change in Operational Excellence (OE)." Procedia CIRP 17, pp. 487 492, 2014.

[13] Powell, D. J., and J. O. Strandhagen. "21 st Century operational excellence: Addressing the similarities and differences between Lean production, Agility and QRM." In 2012 IEEE International Conference on Industrial Engineering and Engineering Management, pp. 449-453, 2012.

[14] Fraser, P, Moultrie, J, and Gregory, M. "The use of maturity models/grids as a tool in assessing product development capability." In IEEE international engineering management conference, vol. 1, pp. 244$249,2002$.

[15] De Bruin, T, Freeze, R., Kaulkarni, U., Rosemann. M. "Understanding the main phases of developing a maturity assessment model", pp. 8-19, 2005

[16] Wendler, R. "Development of the organizational agility maturity model." In 2014 Federated Conference on Computer Science and Information Systems, pp. 1197-1206, 2014.

[17] Shrum, S. "Choosing a CMMI model representation". Cross Talk, 13(7), pp. 6-7, 2000.

[18] Blome, C.,Schoenherr, T., Rexhausen, D. "Antecedents and enablers of supply chain agility and its effect on performance: a dynamic capabilities perspective." International Journal of Production Research 51, no. 4, pp. $1295-1318,2013$.

[19] Gunasekaran, A. "Agile manufacturing: enablers and an implementation framework." Int. J. of Production Research 36, no. 5 pp.1223-1247, 1998.

[20] Bottani, Eleonora. "On the assessment of enterprise agility: Issues from two case studies." International Journal of Logistics: Research and Applications, 12, no. 3, pp. 213-230, 2009.

[21] Vázquez-Bustelo, D., Avella, L., and Fernández, E. "Agility drivers, enablers and outcomes: empirical test of an integrated agile manufacturing model." International Journal of Operations \& Production Management 27, no. 12, pp. 1303-1332, 2007.

[22] Conforto, E., Salum, F., Amaral, D., Silva, S., and Almeida, L. "Can agile project management be adopted by industries other than software development?". Project Management Journal 45, no. 3, pp. 21-34, 2014.

[23] Dikert, K., Paasivaara, M., and Lasseniusm C. "Challenges and success factors for large-scale agile transformations: A systematic literature review." Journal of Systems and Software 119, pp. 87-108, 2016. 